\title{
An Evaluation Model of the Online Learning Effect Based on Fuzzy Mathematics
}

\author{
https://doi.org/10.3991/ijet.v16i10.22749 \\ Cuiping Tao \\ Chongqing Vocational College of Applied Technology, Chongqing, China \\ taocuiping2002@163.com
}

\begin{abstract}
This study derived an evaluation model that overcomes the various problems in the evaluation of online learning effect. Firstly, the influencing factors in the online learning process were discussed in the paper, pointing out the direction to enhance the online learning effect. Next, a multidimensional evaluation index system was established for online learning effect. Meanwhile, the evaluation of online learning effect was treated as a fuzzy evaluation problem with multiple attributes, and an improved evaluation model for online learning effect was proposed based on fuzzy mathematics theory. The proposed model can evaluate the online learning effect effectively and enjoy a good prospect of application.
\end{abstract}

Keywords - Online learning effect, evaluation model, fuzzy mathematics theory, educational decision analysis

\section{Introduction}

Online learning is an important teaching form in modern education. Nowadays, as the modern education technologies are becoming more and more intelligent, online learning is playing an increasingly important role in modern education [1-4]. However, since online learning is affected by a variety of constraints such as hardware facility, software system, teaching management, student self-learning, and course teaching implementation, etc., the manifestations of online learning effect and enhancement strategies have gradually become the focus of attention of field scholars [5-8].

Regardless of manifestations or enhancement strategies, in relevant studies, one important link is the effective and accurate measurement of the online learning effect; however, since many influencing factors are involved and there are fuzzy uncertainties in the various types of factors, the research on the evaluation of online learning effect has become a key content in current relevant studies [9-10].

For example: with college English course as an example, Zhang evaluated and analyzed the effect of a blended teaching mode based on online open courses and proposed a few strategies for enhancing the teaching effect [11]. Gu et al. evaluated and analyzed the online learning effect of medical college students during the COVID-19 epidemic in China [12]. Cheng et al. constructed an online open course learning quality evaluation index system and discussed its application [13]. Wang and Yao gave an overview 
of existing studies concerning the evaluation of online learning based on knowledge graphs, and their paper provided a reference for subsequent studies [14].

Although existing literatures do have some guiding significance for the evaluation of online learning effect, in view of the different research perspectives of different scholars, the existing evaluation index systems of online learning effect are incomplete and imperfect, thus, there is also room for further research. To this end, this paper employed fuzzy mathematics to analyze the online learning effect evaluation problem and improve the evaluation index system and evaluation model, in the hopes of providing a good reference for the effective and accurate evaluation of online learning effect. The content of the paper is arranged as follows: the first part summarizes relevant research concerning the evaluation of online learning effect; the second part analyzes the influencing factors; the third part constructs a multi-dimensional online learning effect evaluation index system; the fourth part establishes the multi-index fuzzy evaluation model of online learning effect; and the fifth part draws the research conclusion.

\section{Influencing Factors of Online Learning Effect}

\subsection{Curriculum design and planning of online courses}

Whether it is online or offline teaching, curriculum design and planning are quite important. On the one hand, curriculum design and planning point out the right direction for course teaching and talent cultivation, it is not merely the course content planning, but a development plan for the cultivation of professional talents, therefore, it is of very important guiding significance. On the other hand, curriculum design and planning list the qualities of professional talents to be cultivated and provide a guarantee for exploring the potential of professional talents. Therefore, in this sense, well designing and planning the curriculum is the primary task of course teaching and the basic condition of professional talent cultivation.

At the same time, it should be noted that online and offline teaching are two different teaching modes, and each has its own characteristics. Online teaching is a useful supplement to offline teaching, and it has unique features in aspects of curriculum system planning, course content design, course teaching scheme formulation, and teaching goal setting, etc. To achieve the ideal online learning effect, this paper proposes that the online teaching should pay special attention to the follows aspects: in terms of curriculum system planning, online teaching should pay more attention to the connection between courses; in terms of course content design, online teaching needs to pay more attention to the sharing of teaching content; in terms of course teaching scheme formulation, online teaching needs to pay more attention to the configurability of teaching schemes; in terms of teaching goal setting, online teaching needs to pay more attention to the social adaptability of the teaching goals. In summary, the curriculum design and planning of online courses is a very important influencing factor of online learning effect. 


\subsection{Construction of online learning platforms}

The implementation of online learning is inseparable from the support of online learning platforms. High quality online learning platforms are the most basic guarantee for the smooth implementation of online learning, and they are the most direct connection between teachers and students. Therefore, developing high-performance online learning platforms to better meet the requirements of online learning is a very important factor for promoting online learning.

The construction of online learning platforms includes two parts: hardware facilities and software systems. The configuration of hardware facilities is the first thing to be considered for the construction of online learning platforms, only high-performance hardware facilities can provide good basic conditions for the construction of online learning platforms; correspondingly, this is also true for the software systems of the online learning platforms, and only by ensuring the god performance of software systems can we build online learning platforms with good adaptability. For this reason, advanced, stable, compatible, and high-performance hardware facilities, as well as intelligent, portable, upgradeable, and easy-to-operate software systems should be prepared for the construction of online learning platforms.

At present, there are quite a few online learning platforms, such as: mooc.chaoxing.com, MOOC, Zhihuishu.com, ke.qq.com, study.baidu.com, dingtalk.com, yuketang.cn, and study.163.com, and these platforms have their respective characteristics, however, in addition to upgrading their hardware facilities, these platforms also need to work on their system compatibility, upgradeability, and portability. For some platforms, although the hardware configuration is good enough, still, the incomplete platform construction might make it difficult to carry out online teaching activities, which also seriously hinders the improvement of the online learning effect.

\subsection{Allocation of online learning resources}

For the promotion of online learning, one necessary condition is the push and display of learning resources, and the push and display operations need to consider the allocation of online learning resources, that is, how to establish the teaching resource library of online learning, including courseware, classic cases, typical content, key knowledge points, content types, and the sustainable development characteristics of course knowledge, etc., moreover, it also includes the online learning resource time arrangement, schedule planning, knowledge point association, and the hierarchical relationship between the content of each chapter, etc. The allocation of online learning resources is a complex project involving not only the relevant characteristics of the course content, but also the teaching status of teachers and the learning status of students, and how to well manage the relationships of these factors and reasonably allocate the online learning resources have a direct impact on the online learning effect, and they can also affect the implementation of online learning activities. 


\subsection{Online learning environment}

Online learning environment refers to two perspectives and multiple links, from the teacher's perspective, it includes links of teaching preparation, teaching execution, teaching feedback, teaching supervision, and teaching evaluation, etc.; while from the student's perspective, it includes links of pre-class preview, classroom learning interaction, classroom activity participation, after-class feedback, and learning evaluation, etc. For both perspectives, the teaching links and learning links are affected by not only one factor, therefore, it's necessary to consider that whether the online learning environment will distract the attention of teachers and students; whether there are conditions for online learning and continuous online learning; whether the online learning environment be able to motivate the learning and teaching enthusiasm of students and teachers; whether the online learning environment can be recognized by teachers and students; whether online learning will take too much extra teaching time and independent learning time and will it be a waste of time; whether online learning will disrupt the teacher's teaching plan or affect the learning status of students; whether the cost of online learning is too must; whether the network fees and learning equipment costs can meet the actual online learning conditions, etc. If the above-mentioned issues are properly handled, the online learning effect would be greatly improved; on the contrary, if the listed issues are not properly solved, it will greatly hinder the implementation of online learning, and thus affecting the online learning effect.

\subsection{Online learning interactivity}

The interactivity of online learning involves several aspects: first, the interaction between teachers, including the sharing of teaching content among teachers, the observability of teaching progress, the controllability of teaching tasks, and the communicability of teaching information. Second, the interaction between teachers and students, the interactive communication and exchange of learning information between teachers and students should be ensured so that it will generate the "teaching-learning resonance", realizing effective knowledge imparting and absorption, and achieving the desired teaching and learning effect. Third, the interaction between students, the information exchange between students should be ensured so that they could be able to fully share the learning information and interact with each other about their learning statues, and thus facilitating the tracking of the online learning status of students. The interactions of these three aspects do not exist independently, therefore, it is necessary to reasonably configure and allocate them to realize a rational status and provide effective support for the improvement of online learning effect. Generally speaking, the interactivity of online learning needs to consider multiple aspects such as the interaction of teachers and students, the information feedback, the timely sharing of teaching information, and the timely monitoring of teaching information. 


\subsection{Faculty of online learning}

The faculty of online learning is the main force for online course teaching, the faculty level is the most basic factor that can reflect the online teaching ability, therefore, improving the faculty level is a good guarantee of online learning effect. The faculty level of online learning is reflected in multiple aspects: first, the teachers should have a solid professional knowledge reserve and good professional qualities and be able to meet the basic requirements of the teaching of professional courses. Second, the teachers should have a broad professional vision and a good ability to expand the professional knowledge, they should be able to impart basic knowledge to students as well as cultivate their innovation ability. Third, the online teaching faculty should form a talent team with a hierarchical structure, so that the development of online teaching could be sustainable. Fourth, the online teaching faculty should have certain online teaching qualities, certain technical skills to use intelligent modern education technologies, and advanced online teaching concepts. Only in this way can the online teaching have a more obvious networked feature, so that students could better immerse themselves into the online learning environment.

\subsection{Course implementation of online learning}

The course implementation of online learning is a progressive factor to ensure the effect of online learning, it is reflected in three aspects: the first aspect is the various links such as teaching tools, methods, organization, progress control, group interaction setting, and classroom atmosphere, etc.; generally, more intelligent teaching tools, more advanced teaching methods, more reasonable teaching organization, more orderly teaching progress control, more realistic group interaction setting, and more enthusiast classroom atmosphere indicate better online learning effect. The second aspect is the integration of online and offline courses; although they do have their respective characteristics, in terms of the development trend of modern education, the development of online courses has become an important link of modern education, and the online and offline courses do not exist independently. Therefore, the online and offline courses should be integrated reasonably so that they could promote the development of each other, and such joint effort will play a positive role in promoting the effect of online learning. The third aspect is students' learning attitude, interest, and self-discipline during the online learning process; in general, better learning attitude, stronger learning interest, and stricter self-discipline indicate better online learning effect.

\section{The Evaluation Index System of Online Learning Effect}

\subsection{Evaluation index selection}

The evaluation of online learning effect involves many influencing factors, and these influencing factors are often of multiple levels, types, and some are fuzzy values. Therefore, in order to get an online learning effect evaluation index system that is close to the 
real situation, the evaluation indexes should be selected reasonably and scientifically. First, the selected indexes should be able to reflect the essential problems in the evaluation process of online learning effect, be able to describe the scientific problems in it, and have clear and rational scientific meanings. Second, the selected indexes should be objective, be able to reflect the real situations of online learning; situations such as subjective imagination or conjecture should be avoided so that the evaluation results of online learning effect could be more in line with the actual implementation situation of online courses. Third, the selected indexes should be uniform and be able to comprehensively reflect the online learning effect from various aspects, and not only focus on one single aspect. Fourth, the selected indexes should have a certain hierarchical structure and be able to describe the hierarchical logical relationship of online learning effect, so that the evaluation framework could be clearer. Fifth, the selected indexes should facilitate the reasonable processing of the qualitative, quantitative, and fuzzy information in the online learning effect analysis.

\subsection{Division of dimensions of online learning effect evaluation}

From the perspective of pedagogy development, although online learning and traditional classroom learning are two different teaching modes, their ultimate goals are the same, that is, to cultivate high-level talents, and improve their learning efficiency and quality to the greatest extent. In essence, the learning processes of the two modes have no fundamental difference, therefore, the evaluation of online learning effect can still be based on the learning process. This paper holds that, the evaluation of online learning effect can be divided into three dimensions according to the learning process, namely the pre-class preparation dimension, the classroom execution dimension, and the afterclass feedback dimension; in this way, the comprehensive evaluation of the online learning effect of the whole process of online course learning could be achieved.

\subsection{Construction of evaluation index system}

Based on the above analysis, an improved online evaluation effect evaluation index system was constructed from the three dimensions of pre-class preparation, classroom execution, and after-class feedback. The pre-class preparation dimension focused on the preparation works before the online course learning, generally, the better the preparation works, the better the online learning effect. The classroom execution dimension focused on the content expression of teachers and students during the online learning process, generally, the stronger the classroom execution ability, the better the online learning effect. The after-class feedback dimension focused on the information exchange and achievement, generally, the timelier the teaching information feedback, the more the teaching achievement, and the better the online learning effect. The specific content of the online learning effect evaluation index system is shown in Table 1. 
Table 1. Online learning effect evaluation index system

\begin{tabular}{|c|c|c|}
\hline Evaluation index system & Evaluation dimension & Evaluation index \\
\hline \multirow{36}{*}{$\begin{array}{l}\text { Online learning effect } \\
\text { evaluation index system }\end{array}$} & \multirow{8}{*}{ Pre-class preparation dimension } & Complete courseware design \\
\hline & & Complete course content planning \\
\hline & & Clear course learning goal \\
\hline & & Rich teaching resource \\
\hline & & Reasonable teaching plan \\
\hline & & $\begin{array}{l}\text { Time spent on online video watching (for } \\
\text { preview before class) }\end{array}$ \\
\hline & & $\begin{array}{l}\text { Learning platform log-in frequency (for } \\
\text { preview before class) }\end{array}$ \\
\hline & & Completion of preview learning tasks \\
\hline & \multirow{16}{*}{ Classroom execution dimension } & $\begin{array}{l}\text { Highlighted key and difficult knowledge } \\
\text { points }\end{array}$ \\
\hline & & $\begin{array}{l}\text { Classroom execution is in line with } \\
\text { teaching objectives and syllabus }\end{array}$ \\
\hline & & $\begin{array}{l}\text { Ability to teach students in accordance } \\
\text { with their aptitude }\end{array}$ \\
\hline & & $\begin{array}{l}\text { Ability to adjust the classroom atmos- } \\
\text { phere }\end{array}$ \\
\hline & & $\begin{array}{l}\text { Frequency and time of asking and an- } \\
\text { swering questions in class }\end{array}$ \\
\hline & & $\begin{array}{l}\text { Frequency and time of online learning } \\
\text { and discussion in class }\end{array}$ \\
\hline & & \begin{tabular}{|l|} 
Time spent on classroom learning \\
\end{tabular} \\
\hline & & Concentration on classroom learning \\
\hline & & Participation in classroom learning \\
\hline & & Completion of classroom learning tasks \\
\hline & & $\begin{array}{l}\text { Times of raising questions actively in } \\
\text { classroom learning }\end{array}$ \\
\hline & & Classroom learning interest \\
\hline & & Classroom learning creative thinking \\
\hline & & Online learning absence rate \\
\hline & & Dissatisfaction with online learning \\
\hline & & Class test failure rate \\
\hline & \multirow{12}{*}{ After-class feedback dimension } & Timeliness of homework submission \\
\hline & & Correct rate of homework \\
\hline & & Pass rate of course exam \\
\hline & & Excellent rate of course exam \\
\hline & & Course dropout rate \\
\hline & & Self-learning ability cultivation \\
\hline & & Practical innovation ability cultivation \\
\hline & & Learning feedback of students \\
\hline & & Answers from teachers \\
\hline & & Times of teaching resource downloading \\
\hline & & Completion of learning goals \\
\hline & & Satisfaction with online learning \\
\hline
\end{tabular}




\section{$4 \quad$ Multi-Index Fuzzy Evaluation Model of Online Learning Effect}

\subsection{Normalization of evaluation indexes}

The evaluation indexes of the above-established system are of various types, and the values of these indexes do not have a uniform dimension, therefore, in order to ensure the reliability and accuracy of the evaluation results, the evaluation indexes of different types and dimensions need to be normalized so that they could have a uniform evaluation standard.

If there are $m$ online learning effect evaluation objects $P$, and $n$ evaluation indexes, then the initial value of the $j$-th evaluation index of the $i$-th evaluation object $P$ is:

$$
V_{i j}=\left[v_{i j}^{l e f}(P), v_{i j}^{r i g}(P)\right], v_{i j}^{l e f}(P) \leq v_{i j}^{r i g}(P)
$$

If the $j$-th evaluation index is a benefit-type index, that is, the greater the value, the better, then its normalized value is:

$$
\left\{\begin{array}{l}
U_{i j}=\left[u_{i j}^{l e f}(P), u_{i j}^{r i g}(P)\right] \\
u_{i j}^{l e f}(P)=\frac{v_{i j}^{l e f}(P)-v_{j}^{\min }(P)}{v_{j}^{\max }(P)-v_{j}^{\min }(P)} \\
u_{i j}^{r i g}(P)=\frac{v_{i j}^{r i g}(P)-v_{j}^{\min }(P)}{v_{j}^{\max }(P)-v_{j}^{\min }(P)} \\
u_{i j}^{l e f}(P) \leq u_{i j}^{r i g}(P)
\end{array}\right.
$$

where, $v_{j}^{\max (P)}$ represents the maximum value of the $j$-th evaluation index in the interval; $v_{j}^{\min (P)}$ represents the minimum value of the $j$-th evaluation index in the interval; the two values need to be selected and determined according to field knowledge.

If the $j$-th evaluation index is a cost-type index, that is, the smaller the value, the better, then its normalized value is:

$$
\left\{\begin{array}{l}
U_{i j}=\left[u_{i j}^{l e f}(P), u_{i j}^{r i g}(P)\right] \\
u_{i j}^{l e f}(P)=\frac{v_{j}^{\max }(P)-v_{i j}^{r i g}(P)}{v_{j}^{\max }(P)-v_{j}^{\min }(P)} \\
u_{i j}^{r i g}(P)=\frac{v_{j}^{\max }(P)-v_{i j}^{l e f}(P)}{v_{j}^{\max }(P)-v_{j}^{\min }(P)} \\
u_{i j}^{l e f}(P) \leq u_{i j}^{\text {rig }}(P)
\end{array}\right.
$$

After all evaluation indexes were normalized, then they had the same analysis standard, which improved the reliability and accuracy of the evaluation results of online learning effect. 


\subsection{Weight assignment of evaluation indexes based on entropy weight method and AHP}

Generally, different evaluation indexes have different degrees of importance, to reflect the differences in the importance degree, the weight values of each index should be determined. The assignment of weight values is often affected by the evaluation objects, the evaluation data, and other subjective and objective factors. On the one hand, the AHP method has the merits of simple calculation and good applicability. If the field experts have good evaluation experience, the obtained index weight values will be more accurate, but since the weight assignment is based on the experience of the experts, the method is relatively subjective to a certain extent [15-18]. On the other hand, the entropy weight method has good objectivity, but the values of the evaluation indexes are usually not that accurate, which will cause certain errors in the calculation results [1921]. Therefore, this paper combined the two methods to obtain the weight values of the evaluation indexes of online learning effect from an overall perspective.

\section{Weight values of evaluation indexes based on AHP}

By referring to the opinions of experts engaging in the field of online education, the online learning effect evaluation indexes were judged and analyzed in pairs, and the judgement value $q_{i j}$ of the i-th evaluation index with respect to the j-th evaluation index was obtained, then the index weight matrix $\boldsymbol{Q}$ could be established as:

$$
\mathbf{Q}=\left[\begin{array}{ccccc}
q_{11} & \cdots & q_{1 i} & \cdots & q_{1 n} \\
\vdots & \vdots & \vdots & \vdots & \vdots \\
q_{i 1} & \cdots & q_{i i} & \cdots & q_{i n} \\
\vdots & \vdots & \vdots & \vdots & \vdots \\
q_{n 1} & \cdots & q_{n i} & \cdots & q_{n n}
\end{array}\right]
$$

where, the value of $q_{i j}$ is generally scored on a scale of 1-9, and its specific meanings and values are shown in Table 2.

Table 2. Meanings of judgement value qij

\begin{tabular}{|c|l|}
\hline Value of $\boldsymbol{q}_{i j}$ & \multicolumn{1}{|c|}{ Relationship between index $\mathbf{i}$ and index $\mathbf{j}$} \\
\hline 1 & The two are equally important \\
\hline 3 & The former is slightly more important than the latter \\
\hline 5 & The former is more important than the latter \\
\hline 7 & The former is much more important than the latter \\
\hline 9 & The former is extremely more important than the latter \\
\hline $2,4,6,8$ & Middle values between two adjacent relationships \\
\hline Reciprocal & Relationship between index $\mathbf{j}$ and index i, there is $q_{j i}=1 / q_{i j}$ \\
\hline
\end{tabular}

The index weight matrix $\boldsymbol{Q}$ was processed:

$$
\left\{\begin{array}{l}
\mathbf{Q} * \mathbf{X}^{T}=\lambda_{\max }(\mathbf{Q}) * \mathbf{X}^{T} \\
\mathbf{X}=\left\{X_{1}, \cdots, X_{j}, \cdots, X_{n}\right\}
\end{array}\right.
$$


where, $\lambda(\boldsymbol{Q})_{\max }$ represents the largest eigenvalue of matrix $\boldsymbol{Q}, \boldsymbol{X}$ represents the eigenvector of matrix $\boldsymbol{Q}$ corresponding to $\lambda(\boldsymbol{Q})_{\max }$.

The index weight matrix $\boldsymbol{Q}$ was subject to consistency check, if it satisfies:

$$
C R=\frac{\lambda_{\max }(\mathbf{Q})-n}{R I *(n-1)}<0.1
$$

It indicates that the index weight matrix $\boldsymbol{Q}$ can meet the requirement of consistency check, then the index weight vector can be expressed as:

$$
\mathbf{W}=\left\{w_{j} \mid 1 \leq j \leq n\right\}=\left\{X_{j} / \sum_{j=1}^{n} X_{j} \mid 1 \leq j \leq n\right\}
$$

If the index weight matrix $\boldsymbol{Q}$ cannot meet the requirement of consistency check, then it needs to be judged and analyzed again until it can meet the requirement of consistency check.

2. Weight values of evaluation indexes based on entropy weight method

If the normalized value of the $j$-th evaluation index of the $i$-th evaluation object $P$ is $U_{i j}=\left[u_{i j}^{l e f}(P), u_{i j}^{r i g}(P)\right]$, it takes:

$$
r_{i j}(P)=\frac{u_{i j}^{l e f}(P)+u_{i j}^{\text {rig }}(P)}{2}
$$

The matrix is obtained as:

$$
\mathbf{R}(P)=\left[\begin{array}{ccccc}
r_{11}(P) & \cdots & r_{1 i}(P) & \cdots & r_{1 n}(P) \\
\vdots & \vdots & \vdots & \vdots & \vdots \\
r_{i 1}(P) & \cdots & r_{i i}(P) & \cdots & r_{i n}(P) \\
\vdots & \vdots & \vdots & \vdots & \vdots \\
r_{n 1}(P) & \cdots & r_{n i}(P) & \cdots & r_{n n}(P)
\end{array}\right]
$$

Then, under the $j$-th evaluation index, the feature proportion of the $i$-th evaluation object $P$ is:

$$
H_{i j}(P)=r_{i j}(P) / \sum_{i=1}^{m} r_{i j}(P)
$$

The information entropy contained in the $j$-th evaluation index is:

$$
E_{j}(P)=-\sum_{i=1}^{m}\left(H_{i j}(P) * \ln H_{i j}(P)\right) / \ln m
$$

Thus, the coefficient of variation of the $j$-th evaluation index can be obtained as:

$$
G_{j}(P)=1-E_{j}(P)
$$


The weight of the $j$-th evaluation index is:

$$
w_{j}=\frac{G_{j}(P)}{\sum_{j=1}^{n} G_{j}(P)}
$$

3. Comprehensive weight values of the evaluation indexes

If the weight of the $\mathrm{j}$-th evaluation index obtained via AHP is marked as $w_{j}(A H P)$, the weight of the $\mathrm{j}$-th evaluation index obtained via the entropy weight method is marked as $w_{j}(E N T R O P Y)$, then the ultimate weight of the $\mathrm{j}$-th evaluation index is:

$$
w_{j}=\alpha * w_{j}(A H P)+\beta * w_{j}(E N T R O P Y)
$$

where: $\alpha$ represents the influence coefficient of subjective factors, $\beta$ represents the influence coefficient of objective factors, their values can be selected according to the actual situation of the evaluation, and there is $\alpha+\beta=1$.

\subsection{Division of evaluation levels}

According to the actual situations, the online learning effect can be divided into different levels. Both too few and too much divided levels would affect the sensitivity of the evaluation results. Too much divided levels would result in unclear boundaries of evaluation results, while too few divided levels would result in too wide ranges of evaluation results. For this reason, under normal conditions, the evaluation results of online learning effect are divided into seven or five levels, which can ensure both the sensitivity and distinguishability of the evaluation results. This paper divided the evaluation results into five levels of excellent, good, medium, qualified, and unqualified, which were marked as $L_{E x e c}, L_{\text {Good }}, L_{\text {Medi }}, L_{Q u a l}$, and $L_{\text {Unqu }}$.

\subsection{Generation of the whitening weight functions}

By applying the gray system theory, the whitening weight functions corresponding to different evaluation levels were established, then gray cluster analysis could be performed on each evaluation object. For the excellent evaluation level, its whitening weight function can be defined as $f_{j}^{L_{\text {Exec }}}\left(x_{i j}(P)\right)=f_{j}^{L_{\text {Exec }}}[0.80,0.90,-,-]$, generally, it takes $x_{i j}(P)=\left(u_{i j}^{l e f}(P)+u_{i j}^{r i g}(P)\right) / 2$, and its structure is shown in Figure 1. 


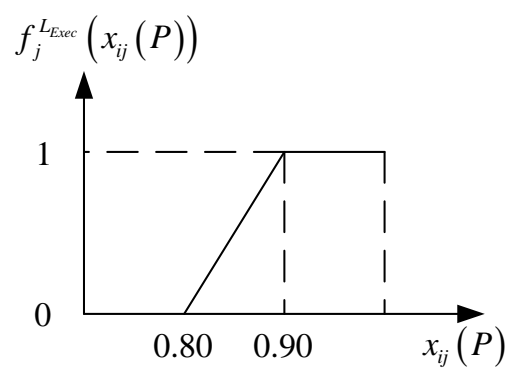

Fig. 1. The structure of the whitening weight function $f_{j}^{L_{E x e c}}\left(x_{i j}(P)\right)$

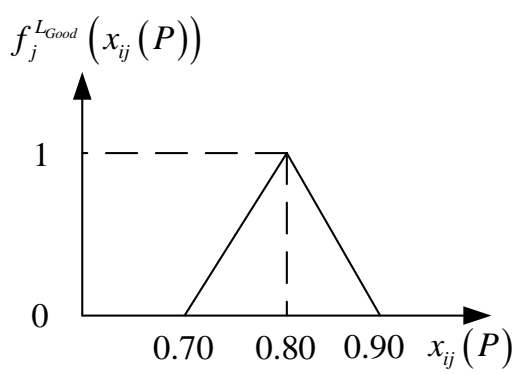

Fig. 2. The structure of the whitening weight function $f_{j}^{L_{G o o d}}\left(x_{i j}(P)\right)$

The corresponding calculation model is:

$$
f_{j}^{L_{\text {Exec }}}\left(x_{i j}(P)\right)=\left\{\begin{array}{lc}
\mathrm{O} & x_{i j}(P) \leq 0.80 \\
1 \mathrm{O}\left(x_{i j}(P)-0.80\right) & 0.90 \leq x_{i j}(P) \leq 1.00 \\
1 & x_{i j}(P) \geq 0.90
\end{array}\right.
$$

For the good evaluation level, its whitening weight function can be defined as $f_{j}^{L_{\text {Good }}}\left(x_{i j}(P)\right)=f_{j}^{L_{\text {Good }}}[0.70,0.80,-, 0.90]$, and its structure is shown in Figure 2.

The corresponding calculation model is:

$$
f_{j}^{L_{\text {cood }}}\left(x_{i j}(P)\right)=\left\{\begin{array}{lc}
0 & x_{i j}(P) \leq 0.70 \wedge x_{i j}(P) \geq 0.90 \\
10\left(x_{i j}(P)-0.70\right) & 0.70 \leq x_{i j}(P) \leq 0.80 \\
10\left(0.90-x_{i j}(P)\right) & 0.80 \leq x_{i j}(P) \leq 0.90 \\
1 & x_{i j}(P)=0.80
\end{array}\right.
$$

For the medium evaluation level, its whitening weight function can be defined as $f_{j}^{L_{\text {Medi }}}\left(x_{i j}(P)\right)=f_{j}^{L_{\text {Medi }}}[0.60,0.70,-, 0.80]$, and its structure is shown in Figure 3. 


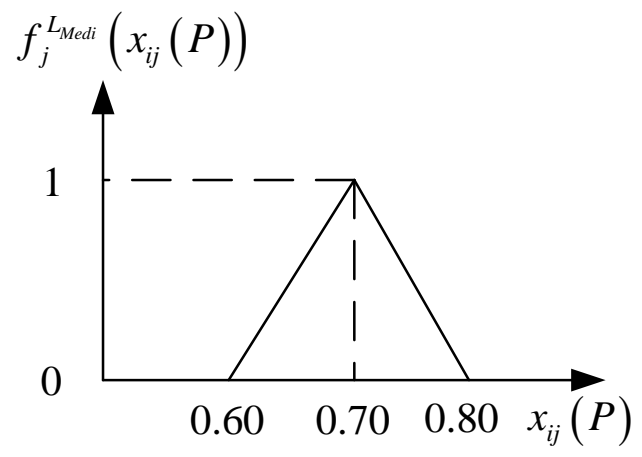

Fig. 3. The structure of the whitening weight function $f_{j}^{L_{M e d i}}\left(x_{i j}(P)\right)$

The corresponding calculation model is:

$$
f_{j}^{L_{\text {Medi }}}\left(x_{i j}(P)\right)= \begin{cases}0 & x_{i j}(P) \leq 0.60 \wedge x_{i j}(P) \geq 0.80 \\ 10\left(x_{i j}(P)-0.60\right) & 0.60 \leq x_{i j}(P) \leq 0.70 \\ 10\left(0.80-x_{i j}(P)\right) & 0.70 \leq x_{i j}(P) \leq 0.80 \\ 1 & x_{i j}(P)=0.70\end{cases}
$$

For the qualified evaluation level, its whitening weight function can be defined as $f_{j}^{L_{\text {Qual }}}\left(x_{i j}(P)\right)=f_{j}^{L_{\text {Qual }}}[0.50,0.60,-, 0.70]$, and its structure is shown in Figure 4.

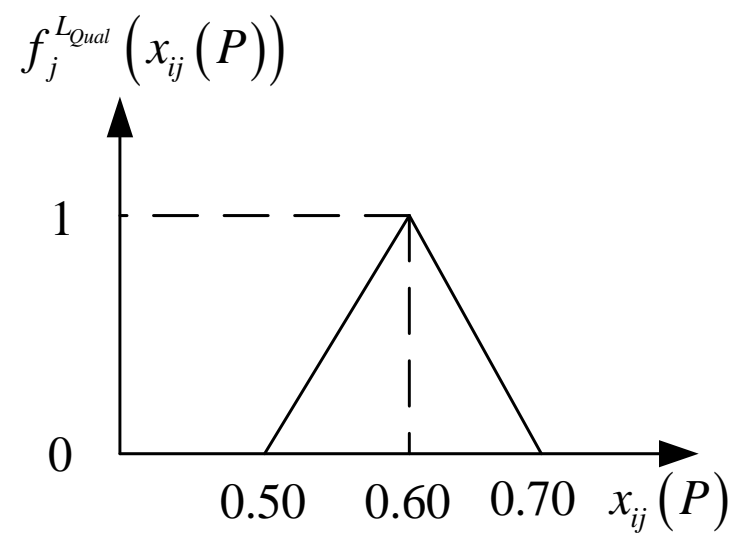

Fig. 4. The structure of the whitening weight function $f_{j}^{L_{\text {Qual }}}\left(x_{i j}(P)\right)$ 
The corresponding calculation model is:

$$
f_{j}^{L_{\text {Qual }}}\left(x_{i j}(P)\right)=\left\{\begin{array}{lc}
0 & x_{i j}(P) \leq 0.50 \wedge x_{i j}(P) \geq 0.70 \\
10\left(x_{i j}(P)-0.50\right) & 0.50 \leq x_{i j}(P) \leq 0.60 \\
10\left(0.70-x_{i j}(P)\right) & 0.60 \leq x_{i j}(P) \leq 0.70 \\
1 & x_{i j}(P)=0.60
\end{array}\right.
$$

For the unqualified evaluation level, its whitening weight function can be defined as $f_{j}^{L_{U n q u}}\left(x_{i j}(P)\right)=f_{j}^{L_{U n q u}}[-,-, 0.50,0.60]$, and its structure is shown in Figure 5.

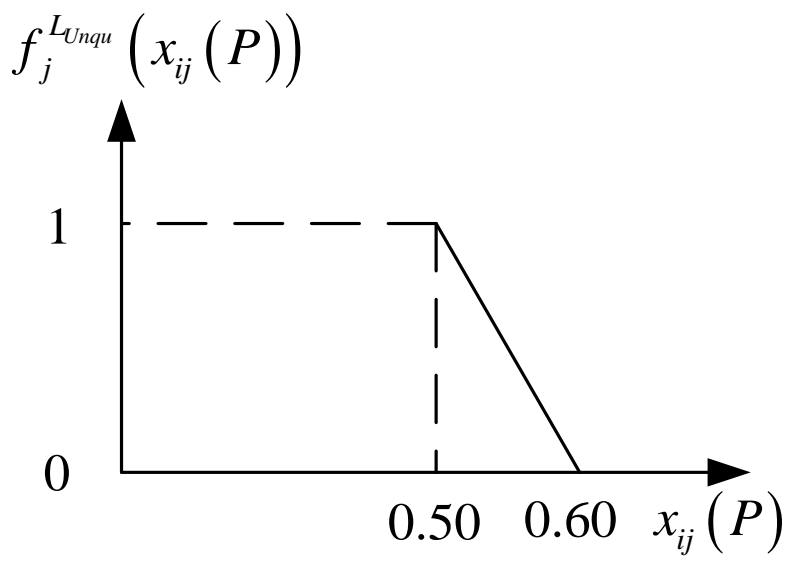

Fig. 5. The structure of the whitening weight function $f_{j}^{L_{U n q u}}\left(x_{i j}(P)\right)$

The corresponding calculation model is:

$$
f_{j}^{L_{\text {nnpu }}}\left(x_{i j}(P)\right)=\left\{\begin{array}{lc}
1 & 0 \leq x_{i j}(P) \leq 0.50 \\
10\left(0.60-x_{i j}(P)\right) & 0.50 \leq x_{i j}(P) \leq 0.60 \\
0 & x_{i j}(P) \geq 0.60
\end{array}\right.
$$

\subsection{Implementation of the evaluation model and the algorithm}

According to the above analysis, the fuzzy membership degree between the evaluation objects and the evaluation levels could be obtained. For the $i$-th evaluation object $P$, assume the fuzzy membership degree of its $j$-th evaluation index to the $k$-th evaluation level is $f_{j}^{k}\left(x_{i j}(P)\right)$, then its comprehensive weighted membership degree $\Psi^{\mathrm{k}}(\mathrm{p})$ is:

$$
\psi_{i}^{k}(P)=\sum_{j=1}^{n}\left(w_{j} * f_{j}^{k}\left(x_{i j}(P)\right)\right)
$$


If it satisfies:

$$
\psi_{i}^{l}(P)=\max _{1 \leq k \leq K} \psi_{i}^{k}(P)
$$

where, $K$ is the number of evaluation levels, $1 \leq k, l \leq K$.

It indicates that the evaluation level of the $i$-the evaluation object $P$ is $l$.

\section{Conclusion}

This paper discussed the evaluation of online learning effect, and the main research works are:

1. Combining with the actual situations of online learning, this paper analyzed the influencing factors in the online learning process and pointed out directions for the improvement of online learning effect, which provided a clear guidance for the development of online learning.

2. Following the scientific, objective, comprehensive, hierarchical, and operable evaluation index selection principles, this paper established a fuzzy evaluation index system of online learning effect considering multiple dimensions of pre-class preview, classroom execution and after-class feedback, which provided a good theoretical support for the evaluation of online learning effect.

3. An improved online learning effect evaluation model was established to realize the fuzzy evaluation and analysis of online learning effect from the perspective of multiattribute decision-making analysis, which provided a solid basis for the quantitative analysis of online learning effect.

\section{Acknowledgement}

Science and Technology Research Program of Chongqing Education Commission in 2019, Vocational Education Cloud Platform on-line and off-line; Children's Games and Guidance \& Innovation of Hybrid Teaching Model of project-based Curriculum. Item number, (Yujiao Kefa [2019]13).

\section{$7 \quad$ References}

[1] Hussein, E., Daoud, S., Alrabaiah, H., Badawi, R. (2020). Exploring undergraduate students' attitudes towards emergency online learning during COVID-19: A case from the UAE. Children and Youth Services Review, 119: 105699. https://doi.org/10.1016/j.childyouth.2 $\underline{020.105699}$

[2] Du, Y.Y., Huang, Q.S. (2020). Research on the quality education of college students and the reform of College Physical Education Curriculum. China Higher Education Research, (6): 58-63. https://doi.org/10.16298/j.cnki.1004-3667.2020.06.11 
[3] Martin, F., Sun, T., Westine, C.D. (2020). A systematic review of research on online teaching and learning from 2009 to 2018. Computers \& Education9 September, 159: 104009. https://doi.org/10.1016/j.compedu.2020.104009

[4] Ritanjali, R., Srivastabva, P.R., Sharma, D. (2018). Online learning: Adoption, continuance, and learning outcome-A review of literature. International Journal of Information Management, 43: 1-14. https://doi.org/10.1016/j.ijinfomgt.2018.05.005

[5] Chen, F.S., Ke, H.S., Chen, Y.C. (2020). Online Learning as a Panacea: An Empirical Study to Discuss Problem-Based Cooperative Learning in Taiwan, International Journal of Emerging Technologies in Learning, 15(18): 251-259. https://doi.org/10.3991/ijet.v15i18.15079

[6] Bai, X. (2020). Research on Online Classroom Optimization Strategy Based on Cluster Analysis of Network Learning Behavior. Journal of Jilin Institute of Chemical Technology, 37(8): 44-48. https://doi.org/10.16039/j.cnki.cn22-1249.2020.08.011

[7] Elzainy, A., Sadik, A.E., Abdulmonem, W.A. (2020). Experience of e-learning and online assessment during the COVID-19 pandemic at the College of Medicine, Qassim University. Journal of Taibah University Medical Sciences, 15(6): 456-462. https://doi.org/10.1016/ j.jtumed.2020.09.005

[8] Almusharraf, N.M., Khahro, S.H. (2020). Students' Satisfaction with Online Learning Experiences during the COVID-19 Pandemic, International Journal of Emerging Technologies in Learning, 15(21): 246-267. https://doi.org/10.3991/ijet.v15i21.15647

[9] Sun, Y., Chai, R.Q. (2020). An early-warning model for online learners based on user portrait. Ingénierie des Systèmes d'Information, 25(4): 535-541. https://doi.org/10.18280/isi.2 $\underline{50418}$

[10] Saddhono, K., Setyawan, B.W., Raharjo, Y.M., Devilito, R. (2020). The diagnosis of online game addiction on Indonesian adolescent using certainty factor method. Ingénierie des Systèmes d'Information, 25(4): 191-197. https://doi.org/10.18280/isi.250206

[11] Zhang, J.H. (2018). Research on the effect evaluation and promotion strategy of College English blended teaching based on online open course. 24(25): 175-176. https://doi.org/ 10.3969/j.issn.1009-0843.2018.25.169

[12] Gu, F., Qi, W.X., Meng, C., Li, Y.J., Xue, S.L., Yin, Z.D., Li, M.Y., Lan, X.L., Zhang, M. (2020). Evaluation of learning outcome by online teaching in medical undergraduates during COVID-19 pandemic. Chinese Journal of Medical Education, 40(9): 726-730. https://doi .org/10.3760/cma.j.cn115259-20200413-00554

[13] Cheng, Y.L., Tan, A.P. (2020). The Construction and application of evaluation index system for online open course learning quality. Contemporary Vocational Education, (1): 62-69. https://doi.org/10.16851/j.cnki.51-1728/g4.20200115.003

[14] Wang, C.F., Yao, M.M. (2019). Research Review of Network Learning Evaluation Based on Knowledge Map. Software Guide, 18(5): 9-12. https://doi.org/10.11907/rjdk.182400

[15] Luca, S.D., Pace, R.D., Bruno, F. (2020). Accounting for attitudes and perceptions influencing users' willingness to purchase Electric Vehicles through a Hybrid Choice Modeling approach based on Analytic Hierarchy Process. Transportation Research Procedia, 45: 467474. https://doi.org/10.1016/j.trpro.2020.03.040

[16] Mathew, M., Chakrabortty, R.K., Ryan, M.J. (2020). A novel approach integrating AHP and TOPSIS under spherical fuzzy sets for advanced manufacturing system selection. Engineering Applications of Artificial Intelligence, 96: 103988. https://doi.org/10.1016/j.engappai.2020.103988

[17] Colak, H.E., Memisoglu, T., Gercek, Y. (2019). Optimal site selection for solar photovoltaic (PV) power plants using GIS and AHP: A case study of Malatya Province, Turkey. Renewable Energy, 149: 565-576. https://doi.org/10.1016/j.renene.2019.12.078 
[18] Lee, Y., Son, S., Park, H. (2020). Analysis of Korea's nuclear R\&D priorities based on private Sector's domestic demand using AHP. Nuclear Engineering and Technology, 52(11): 2660-2666. https://doi.org/10.1016/j.net.2020.04.029

[19] Allahverdyan, A.E., Galstyan, A., Abbas, A.E., Struzik, Z.R. (2018). Adaptive decision making via entropy minimization. International Journal of Approximate Reasoning, 103: 270-287. https://doi.org/10.1016/j.ijar.2018.10.001

[20] Oluah, C., Akinlabi, E.T., Njoku, H.O. (2020). Selection of phase change material for improved performance of Trombe wall systems using the entropy weight and TOPSIS methodology. Energy and Buildings, 217: 1-10. https://doi.org/10.1016/j.enbuild.2020.109967

[21] Del, M.S.T.T., Tabrizi, S.K. (2020). A methodological assessment of the importance of physical values in architectural conservation using Shannon entropy method. Journal of Cultural Heritage, 44: 135-151. https://doi.org/10.1016/j.culher.2019.12.012

\section{Author}

Cuiping Tao was born in July 1981 in Fengdu County, Chongqing, lecturer, graduated from Shenyang Normal University in 2013 with a master's degree in preschool education. She is currently working at Chongqing Vocational College of Applied Technology as director of pre-school Education Department. Her main research areas: physical and mental health development and education of pre-school children, pre-school children play guidance. In recent years, he has hosted three projects at the provincial and ministerial level in Chongqing: Chongqing Education and teaching reform project in 2018: A study on the strategies for improving the professional practice ability of rural kindergarten teachers in the new era Foshan as an example in Hechuan District; 2019 science and Technology Research Project of Chongqing Education Commission: "online and off-line Vocational Education Cloud Platform" child play and guidance" Project Hybrid Model Innovation; 2020 Chongqing Higher Vocational and Technical Education Research Association Project: Animation Elements into the construction of child play curriculum practical research. She has written and published a monograph and several academic papers related to preschool education in many domestic publishing houses. Email: taocuiping2002@163.com.

Article submitted 2021-02-19. Resubmitted 2021-03-21. Final acceptance 2021-03-22. Final version published as submitted by the authors. 